RISUS - Journal on Innovation and SUstainability ISSN 2179-3565

(1) ramaguch

:

霓

(2)

(1)

\title{
A Importância na Uniformidade da Tributação dos Recursos Hídricos
}

\author{
Nathieli Dos Santos, Fernando de Almeida Santos Correio \\ Pontifícia Universidade Católica de São Paulo, FMU, \\ Faculdades Integradas Rio Branco, São Paulo, Brasil \\ E-mail: nathi0601@hotmail.com, almeidasantos@pucsp.br
}

Resumo: Esta pesquisa apresenta e analisa a situação a respeito da tributação, com foco na escassez dos recursos hídricos. O trabalho, inicialmente bibliográfico, aborda o conceito sustentabilidade, além de conceituar tributos e classificá-los. Posteriormente, analisa a Lei 12.183 de 29 de dezembro de 2005, promulgada para o Estado de São Paulo, sobre a cobrança pela utilização dos recursos hídricos. Conclui-se que é de grande importância que medidas sejam tomadas por meio do governo federal, de uma forma geral, onde políticas de investimentos sustentáveis possam direcionar a sociedade e as empresas, em novos hábitos, mais conscientes e de uma forma sustentável e, desta forma, evitar a escassez deste recurso fundamental à vida. Palavras-chave: Escassez, Sustentabilidade, Recursos Hídricos

Recebido em: 07-03-2015

Aceito em: 05-12-2015 
RISUS - Journal on Innovation and SUstainability ISSN 2179-3565

C) Mamacucin

$\because:$

娄

(1)

RISUS - Journal on Innovation and Sustainability Volume 6, número 3 - 2015

ISSN: 2179-3565

Editor Científico: Arnoldo José de Hoyos Guevara Editora Assistente: Nara Pamplona Macedo Avaliação: Melhores práticas editoriais da ANPAD

\title{
The Importance of having a Uniform Water Resources Tax
}

\author{
Nathieli Dos Santos, Fernando de Almeida Santos Correio \\ Pontifícia Universidade Católica de São Paulo, FMU, \\ Faculdades Integradas Rio Branco, São Paulo, Brasil \\ E-mail: nathi0601@hotmail.com, almeidasantos@pucsp.br
}

\begin{abstract}
This paper leads with the study concerning the scarcity of water resources and focusing on taxes policies at the State of Sao Paulo, Brazil. Conceptually this work deals with sustainability, but focuses on taxes and classifies them regarding the use of water resources based on the Law 12.183 of December 29, 2005, promulgated in the State of São Paulo. The study shows the very important need that measures be taken by the federal government, in general, so that a change on sustainable investment policies may transform society and businesses habits, to become more conscious and sustainable; and so prevent the shortage of this vital resource for life.
\end{abstract}

Keywords: Water Resources, Scarcity, Sustainability

Received: 07-03-2015

Accept: 05-12-2015 


\section{INTRODUÇÃO}

Sustentabilidade é muito abordada nos dias atuais em diversas áreas. A água, por sua vez, é um dos principais recursos abordados por sua escassez. Portanto, são necessários certos cuidados para que todas as gerações possam usufruir desse recurso natural e há a preocupação com formas de utilização mais racional, podendo ser uma alternativa, a tributação.

Sendo assim, o trabalho tem por objetivo estudar e diagnosticar de que forma se pode atribuir um tributo a fim de evitar que água como recurso natural e fonte de vida deixe de existir para sobrevivência de gerações futuras.

Embora o Brasil seja privilegiado, com $12 \%$ da água doce superficial no mundo, os brasileiros, que sempre se consideraram dotados de fontes inesgotáveis vêem algumas de suas cidades sofrerem falta de água.

Diante das agressões que o meio ambiente vem sofrendo, seja estas por atitudes individuais ou pelas empresas, a preocupação torna-se cada vez mais constante. $E$, com este cenário, providências imediatas precisam ser tomadas a fim de deter o uso desenfreado dos recursos naturais e a favor da sustentabilidade, que busca uma harmonia com o meio ambiente, não comprometendo gerações futuras.

Dentre os recursos naturais, o elemento mais importante e indispensável para a vida, e, consequentemente, para a produção, é a água, com isso, questões sobre conservação e preservação dos recursos hídricos e do meio ambiente vêm sendo discutidas nos órgãos governamentais.

\section{A GESTÃO DA ÁGUA E A SUSTENTABILIDADE}

O princípio da sustentabilidade surge no contexto da globalização como a marca de um limite e o sinal que reorienta o processo civilizatório da humanidade. A crise ambiental veio questionar a racionalidade e os paradigmas teóricos que impulsionaram e legitimaram o crescimento econômico, negando a natureza. A sustentabilidade ecológica aparece assim como um critério normativo para a reconstrução da ordem econômica, como uma condição para a sobrevivência humana e um suporte para chegar a um desenvolvimento duradouro, questionando as próprias bases da produção, conforme Leff (2001, p. 15): "O conceito de sustentabilidade surge, portanto, de reconhecimento da função de suporte da natureza, condição e potencial do processo de produção".

O discurso do desenvolvimento sustentável foi sendo legitimado, oficializado e difundido amplamente com base na Conferência das Nações Unidas sobre o Meio Ambiente e o Desenvolvimento, celebrada no Rio de Janeiro, em 1992. Mas a consciência ambiental surgiu nos anos 60 com a Primavera Silenciosa de Rachel Carson, e se expandiu nos anos 70, depois da Conferência das Nações Unidas sobre o Meio Ambiente Humano, celebrada em Estocolmo, em 1972. Naquele momento é que foram assinalados os limites da racionalidade econômica e os desafios da degradação ambiental ao projeto civilizatório da modernidade. A escassez, alicerce da teoria e prática econômica, converteu-se numa escassez global que já não se resolve mediante o progresso técnico, pela substituição de recursos escassos por outros mais abundantes ou pelo aproveitamento de espaços não saturados para o depósito dos rejeitos gerados pelo crescimento desenfreado da produção. (LEFF, 2001).

No início da década de 1990, grandes expectativas se formaram em torno de um encontro 
que parecia destinado a entrar para a história: a Conferência das Nações Unidas para o Meio Ambiente e Desenvolvimento (CNUMAD), também conhecida como Rio 92, Eco-92 ou Cúpula da Terra. O evento reuniu 178 países no Rio de Janeiro, com a participação da sociedade civil, de ONGs e chefes de Estado. Antes negligenciada em nome da segurança nacional, a questão ambiental alcançou notoriedade, abraçando-se à ideia de desenvolvimento sustentável como alternativa à exploração predatória. (Academia Pearson, 2010).

Santos (Santos, 2009) define sustentabilidade da seguinte forma: "A sustentabilidade significa a qualidade de se sustentar. A palavra é utilizada no sentido de caracterizar a busca de forma sustentável do planeta. Esta busca envolve aspectos sociais, culturais, financeiros, humanas e ambientais".

Segundo Donaire (in Braga, 2007), cada vez a questão ambiental está se tornando matéria obrigatória das agendas dos executivos da empresa, sendo que a globalização dos negócios, a internacionalização dos padrões de qualidade descritos na série ISO 14000, a conscientização crescente dos atuais consumidores e a disseminação da educação ambiental nas escolas permitem antever que a exigência futura que farão os futuros consumidores em relação à preservação do meio ambiente e à qualidade de vida deverão intensificar-se.

Diante disso, as organizações deverão, de maneira acentuada, incorporar a variável ambiental na prospecção de seus cenários e na tomada de decisão, além de manter uma postura responsável de respeito à questão ambiental.

Ainda, conforme Braga (2007), o objetivo geral da ISO 14000 é fornecer assistência para as organizações na implantação ou no aprimoramento de um Sistema de Gestão Ambiental (SGA), pois a ISO é consistente com a meta de desenvolvimento sustentável e é compatível com diferentes estruturas culturais, sociais e organizacionais.

Robles Jr. e Bonelli (in Santos, 2009) afirmam que a A ISO 14000 oferece diretrizes para o desenvolvimento e a implementação de princípios e sistemas de gestão ambiental, bem como à sua coordenação com outros sistemas gerenciais, podendo ser aplicáveis a qualquer organização, independente do tamanho, tipo ou nível de maturidade, que esteja interessada em desenvolver, implementar e/ou aprimorar um SGA (Sistema de Gestão Ambiental).

$E$, para complementar, Valle considera: "A gestão do meio ambiente em uma empresa deve estar bem integrada com os demais setores que regem o negócio".

Destaca-se entre as vantagens que levam uma empresa à implantação de um sistema de gestão ambiental:

- $\quad$ Pode facilitar acesso a financiamento;

- $\quad$ Conservação de energia e recurso natural, podendo até economizar;

- $\quad$ Redução de acidentes ambientais;

- Melhoria da imagem, relacionada às questões ambientais;

- $\quad$ Redução de perdas e de desperdício;

- $\quad$ Redução de riscos de sanções pelo Poder Público;

- Melhor relação com a comunidade externa, que pode não ser cliente, mas pode influenciá-lo.

Portanto, a gestão da Qualidade está relacionada à melhor utilização dos recursos, em especial ao controle do consumo da água. 


\section{TRIBUTOS: CONCEITOS E CLASSIFICAÇÃO}

De acordo com art. $3^{\circ}$ do Código Tributário Nacional, tributo apresenta a seguinte definição: "Tributo é toda prestação pecuniária compulsória, em moeda ou cujo valor nela se possa exprimir, que não constitua sanção de ato ilícito, instituída em lei e cobrada mediante atividade administrativa plenamente vinculada."

De acordo com a Constituição da República Federativa do Brasil de 1988, o tributo classifica-se nas seguintes espécies tributárias:

- Impostos, são os tributos cuja obrigação tem por fato gerador uma situação independente de qualquer atividade estatal específica, relativa ao contribuinte;

- $\quad$ Taxas, em razão do exercício do poder de polícia ou pela utilização, efetiva ou potencial, de serviços públicos específicos e divisíveis, prestados ao contribuinte ou postos à sua disposição;

- $\quad$ Contribuição de melhoria, decorrente de obras públicas.

A Constituição Federal afirma, ainda, que sempre que possível, os impostos terão caráter pessoal e serão graduados segundo a capacidade econômica do contribuinte.

O artigo 77 do Código Tributário Nacional discorre sobre taxas da seguinte maneira:

Art. 77. As taxas cobradas pela União, pelos Estados, pelo Distrito Federal ou pelos Municípios, no âmbito de suas respectivas atribuições, têm como fato gerador o exercício regular do poder polícia, ou a utilização, efetiva ou potencial, de serviço público específico e divisível, prestado ao contribuinte, ou posto a sua disposição. Parágrafo único. A taxa não pode ter base de cálculo ou fato gerador idênticos aos que correspondam a imposto, nem ser calculada em função do capital das empresas.

Um fato que deve ser observado consiste na afirmação de Sukhdev (2013) de que a Tributação deve ser sobre recursos: portanto deve se cobrar sobre os males causados, e não sobre os bens produzidos. Este fato destaca a importância sobre a reflexão em relação à este tributo.

Pode-se afirmar que o tributo é a principal fonte de arrecadação da união, dos estados, dos municípios e do Distrito Federal. É por meio desses valores que obras públicas são financiadas, ou seja, é o retorno em forma de serviços básicos como saúde, educação e saneamento, entre outros, ao contribuinte.

\section{METODOLOGIA}

Esta pesquisa é dedutiva, sendo que para o desenvolvimento foi feito levantamento bibliográfico, por meio de livros, dissertações, teses, sites e monografias, além de pesquisa sobre a proposta do tributo.

Portanto, o trabalho, inicialmente bibliográfico, aborda o conceito sustentabilidade e a sua relação com a gestão, além de conceituar tributo e classificá-los.

Ao final, a partir da Lei 12.183, de 29 de dezembro de 2005, que dispõe sobre a cobrança pela utilização dos recursos hídricos do domínio do Estado de São Paulo, os procedimentos para fixação dos seus limites, foi realizada uma análise, por meio de um estudo de caso, com intenção de demonstrar que a tributação deve ser implantada de forma que possa regular a questão 
da futura escassez da água e que é necessário uma política nacional com o objetivo de evitar guerras fiscais ou abusos.

Portanto, foi realizada uma análise dos aspectos legais e ao final são apresentadas as considerações sobre o tema.

\section{TRIBUTAÇÃO, A PARTIR DA ANÁLISE DA LEI ESTADUAL no 12.183/2005, DO ESTADO DE SÃO PAULO}

Conforme o Instituto Socioambiental, a Região Metropolitana de São Paulo (RMSP) já apresenta sérios problemas para garantir água em quantidade e qualidade adequada para seus habitantes, onde a má gestão desse recurso resulta na destruição de importantes fontes de água, altas taxas de perda e destruição de seus mananciais pela expansão urbana. Para dar conta do abastecimento atual de sua população, a RMSP importa mais da metade da água que consome da Bacia do Rio Piracicaba, através do Sistema Cantareira - que está a mais de $70 \mathrm{Km}$ do centro de São Paulo e conta com seis represas interligadas por túneis. O restante da água é produzida pelos mananciais que ainda restam na região - em especial Billings, Guarapiranga e Sistema Alto Tietê - e que sofrem intenso processo de ocupação, resultante da expansão da mancha urbana dos municípios que fazem parte da Grande São Paulo. São oito sistemas produtores de água, que produzem cerca 65 mil litros de água por segundo (que totalizam 5,6 bilhões de litros de água por dia), uma quantidade de água suficiente para encher 2.250 piscinas olímpicas por dia.

Segundo Jannuzzi, a população de São Paulo aumentou em mais de nove vezes seu tamanho, em 50 anos, de 1900 a 1950, passando de cerca de 240 mil habitantes para 2,2 milhões. Isso representou, em termos médios, uma taxa de crescimento de $4,5 \%$ anuais. Foi um processo extremamente rápido, alimentado por numerosos contingentes de migrantes do interior do estado, de Minas Gerais, dos estados do Nordeste e mesmo de outros países (Itália, Portugal, Espanha, Japão, Oriente etc).

Preocupado com estes fatores foi aprovada a Lei $n 012.183$ que dispõe sobre a cobrança pela utilização dos recursos hídricos do domínio do Estado de São Paulo, os procedimentos para fixação dos seus limites, condicionantes e valores e dá outras providências.

Do objetivo e da implantação da cobrança, o artigo 1ำ apresenta os seguintes objetivos da cobrança pela utilização dos recursos hídricos:

I - reconhecer a água como bem público de valor econômico e dar ao usuário uma indicação de seu real valor;

II - incentivar o uso racional e sustentável da água;

III - obter recursos financeiros para o financiamento dos programas e intervenções contemplados nos planos de recursos hídricos e saneamento, vedada sua transferência para custeio de quaisquer serviços de infra-estrutura;

IV - distribuir o custo sócio-ambiental pelo uso degradador e indiscriminado da água;

V - utilizar a cobrança da água como instrumento de planejamento, gestão integrada e descentralizada do uso da água e seus conflitos. 
O artigo 1, que objetiva que se reconheça o valor desse recurso indispensável à vida, também tem o intuito de que seu uso seja racional, além de gerar recursos capazes de financiar planos de recursos hídricos e saneamento e, por fim, desenvolver um uso sustentável da água.

Programas, projetos, serviços e obras poderão ser implementados, por meio da cobrança pela utilização dos recursos hídricos, ou seja, essa arrecadação possui caráter regulatório, e não simplesmente com finalidade de arrecadar.

Cabe a Assembleia Legislativa do Estado, acompanhar e fiscalizar a aplicação dos recursos arrecadados, através de suas Comissões competentes, obedecendo a legislação vigente de cada um dos comitês de bacias.

O artigo 5으, afirma que todos aqueles que se utilizam dos recursos hídricos estão sujeitos a cobrança. E ainda apresenta os seguintes parágrafos.

$\S 1$ ㅇ - A utilização de recursos hídricos destinada às necessidades domésticas de propriedades e de pequenos núcleos populacionais distribuídos no meio rural estará isenta de cobrança quando independer de outorga de direito de uso, conforme legislação específica.

$\S 2$ - Os responsáveis pelos serviços públicos de distribuição de água não repassarão a parcela relativa à cobrança pelo volume captado dos recursos hídricos aos usuários finais residenciais, desde que seja comprovado o estado de baixa renda do consumidor, nas condições a serem definidas em regulamento.

§ 3ㅇ - A cobrança para fins de geração de energia elétrica seguirá o que dispuser a legislação federal.

$\S 4$ ㅇ - A utilização de recursos hídricos por micro e pequenos produtores rurais será isenta de cobrança, conforme dispuser a regulamentação.

$\S 5$ o - vetado.

Conforme artigo 6으, a fixação dos valores de cobrança deve obedecer aos procedimentos apresentados a seguir:

I - estabelecimento dos limites e condicionantes pelo Conselho Estadual de Recursos Hídricos;

II - proposta, pelos Comitês de Bacia Hidrográfica, dos programas quadrienais a serem efetivamente realizados, das parcelas dos investimentos a serem cobertos com o produto da cobrança, e dos valores a serem cobrados na Bacia;

III - referenda, pelo Conselho Estadual de Recursos Hídricos, das propostas dos Comitês, de programas quadrienais de investimentos e dos valores da cobrança;

IV - aprovação e fixação dos valores a serem aplicados em cada Bacia Hidrográfica, por decreto do Governador do Estado. 
Ainda conforme artigo 6은

§ 1ㅇ - Da proposta, pelo Comitê de Bacia Hidrográfica, dos valores a serem cobrados na Bacia, caberá recurso administrativo ao Conselho Estadual de Recursos Hídricos, na forma a ser definida em regulamento.

$\S 2$ - As decisões do Conselho Estadual de Recursos Hídricos e dos Comitês de Bacia sobre a fixação dos limites, condicionantes e valores da cobrança pela utilização dos recursos hídricos serão tomadas por maioria simples, mediante votos dos representantes da Sociedade Civil, dos Municípios e do Estado, os quais terão os seguintes pesos:

1 - 40\% (quarenta por cento), os votos dos representantes de entidades da sociedade civil, fixado em $70 \%$ (setenta por cento), no contexto destas, o peso dos votos das entidades representativas de usuários pagantes de recursos hídricos;

2 - 30\% (trinta por cento), os votos dos representantes dos Municípios;

3 - 30\% (trinta por cento), os votos dos representantes do Estado.

O artigo 70 afirma que a cobrança deve ser realizada pela entidade responsável pela outorga de direito de uso nas Bacias Hidrográficas desprovidas de Agências de Bacias e pelas Agências de Bacias.

Os Comitês de Bacia deverão definir o modo e a periodicidade de cobrança, em função das respectivas peculiaridades e conveniências, conforme exposto no artigo 8‥

Dos critérios gerais para a cobrança, conforme artigo 9 a fixação dos valores a serem cobrados pela utilização dos recursos hídricos considerará:

I - na captação, extração e derivação:

a natureza do corpo d'água - superficial e subterrâneo;

b) a classe de uso preponderante em que estiver enquadrado o corpo d'água no local do uso ou da derivação;

c) a disponibilidade hídrica local;

d) o grau de regularização assegurado por obras hidráulicas;

e) o volume captado, extraído ou derivado e seu regime de variação;

f) o consumo efetivo ou volume consumido, calculado pela diferença entre o volume captado e o volume devolvido, dentro dos limites da área de atuação do Comitê de Bacia, ou pelo volume exportado para fora desses limites, segundo o tipo de utilização da água e seu regime de variação;

g) a finalidade a que se destinam;

h) a sazonalidade;

i) as características dos aqüíferos;

j) as características físico-químicas e biológicas da água no local;

k) a localização do usuário na Bacia;

I) as práticas de conservação e manejo do solo e da água; 
II - na diluição, transporte e assimilação de efluentes:

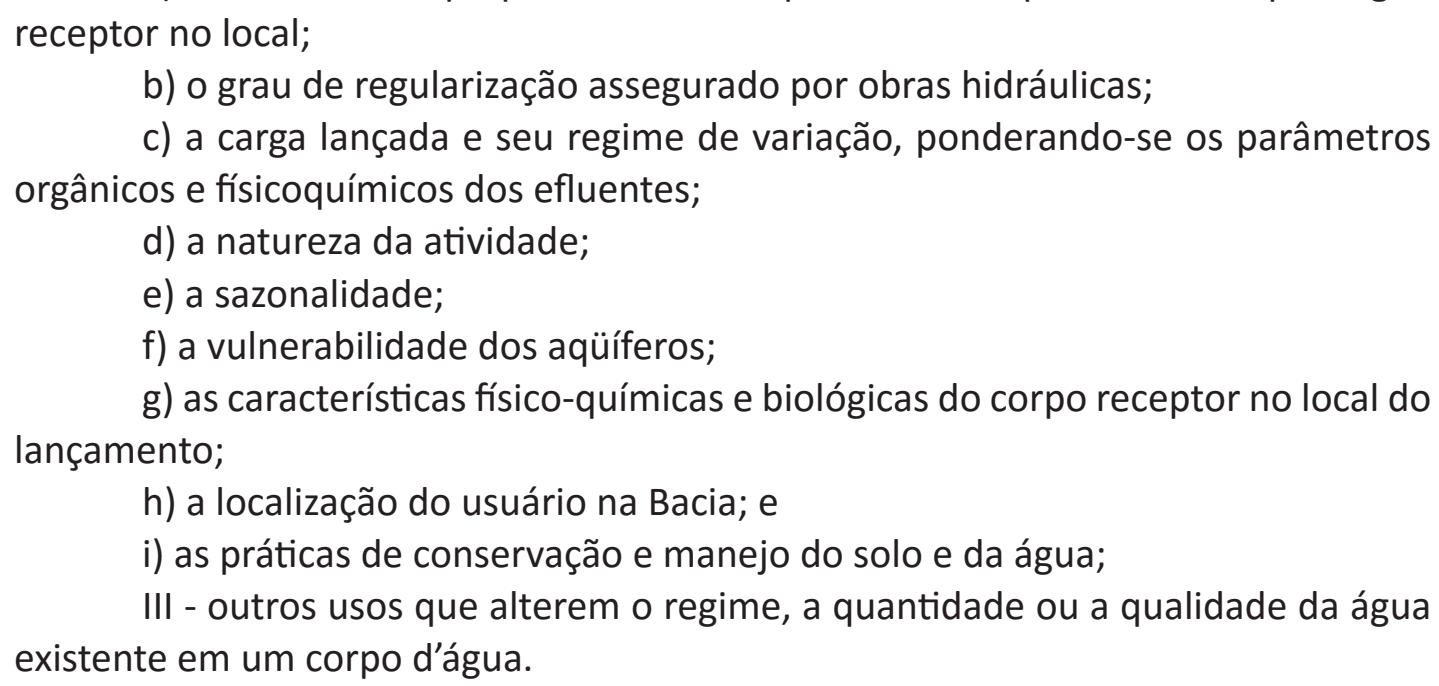
receptor no local;

b) o grau de regularização assegurado por obras hidráulicas;

c) a carga lançada e seu regime de variação, ponderando-se os parâmetros orgânicos e físicoquímicos dos efluentes;

d) a natureza da atividade;

e) a sazonalidade;

f) a vulnerabilidade dos aqüíferos;

g) as características físico-químicas e biológicas do corpo receptor no local do lançamento;

h) a localização do usuário na Bacia; e

i) as práticas de conservação e manejo do solo e da água;

III - outros usos que alterem o regime, a quantidade ou a qualidade da água existente em um corpo d'água.

a) a classe de uso preponderante em que estiver enquadrado o corpo d'água

A fixação dos valores a serem cobrados terá por base o volume captado, extraído, derivado e consumido, assim como a carga dos efluentes lançados nos corpos d'água, podendo os Comitês de Bacia propor a diferenciação dos valores a serem cobrados, em função de parâmetros e critérios que deverão ser definidos em regulamento, que abranjam não somente a disponibilidade dos recursos hídricos como também a qualidade dos mesmos, de acordo com as peculiaridades das respectivas unidades hidrográficas. E ainda, adotar mecanismos de compensação e incentivos para aqueles usuários que de alguma forma devolverem a água com uma qualidade acima daquela determinada em legislação e em normas regulamentares.

Das bases de cálculo para a cobrança, o artigo 10 afirma que as entidades responsáveis pela outorga de direito de uso e as Agências de Bacias devem manter cadastro integrado de dados e informações, que deverão ser obrigatoriamente informados pelos usuários, possibilitando determinar as quantidades sujeitas à cobrança, facultado ao usuário acesso aos seus dados cadastrais.

Conforme artigo 11 o volume consumido deve ser avaliado dependendo da forma que a água for utilizada, pela multiplicação do volume captado, extraído ou derivado, por meio de um fator de consumo, que será definido em regulamento.

$\mathrm{O}$ artigo 12 discorre:

O valor a ser cobrado por captação, extração, derivação e consumo resultará da multiplicação dos respectivos volumes captados, extraídos, derivados e consumidos pelos correspondentes valores unitários, e pelo produto dos coeficientes que considerem os critérios estabelecidos no artigo 9으, respeitado o limite máximo correspondente a 0,001078 UFESP (um mil e setenta e oito milionésimos de UFESP) por $\mathrm{m}^{3}$ captado, extraído ou derivado.

Parágrafo único - Na hipótese de extinção da UFESP, o limite a que se refere o "caput" será definido com base na legislação que vier a substituí-la. 
Artigo 13: Na diluição, transporte e assimilação de efluentes, os parâmetros a serem considerados e as cargas referentes a cada um deles, por atividade, serão definidos em regulamento.

Artigo 14: A carga lançada será avaliada, em função da atividade do usuário, pela multiplicação da carga produzida por um fator de tratamento, conforme condições a serem definidas em regulamento.

A cobrança pela utilização dos recursos hídricos para a diluição, transporte e assimilação das cargas lançadas nos corpo d'água se dará por meio da soma das parcelas de cada parâmetro, obedecendo o teto de 3 vezes o valor que deverá ser cobrado por captação, extração, derivação e consumo, desde que atendam os padrões de lançamentos que a legislação vigente estabelecer, de acordo com o artigo 15.

Em seu artigo 16 afirma-se que, caso a cobrança seja considerada inconsistente, as quantidades calculadas poderão ser revistas com base em valores resultantes de medição direta dos volumes captados, extraídos, derivados, consumidos e das cargas lançadas.

Das sanções, o artigo 17 afirma que, caso os valores não sejam pagos até a data do vencimento, sem prejuízo de sua cobrança administrativa ou judicial, irá acarretar:

I - a suspensão ou perda do direito de uso, outorgado pela entidade competente, a critério do outorgante, na forma a ser definida em regulamento;

II - o pagamento de multa de $2 \%$ (dois por cento) sobre o valor do débito;

III - o pagamento de juros moratórios de $1 \%$ (um por cento) ao mês.

Conforme artigo 18, a falsa informação de dados relativos à vazão captada, extraída, derivada ou consumida e à carga lançada pelo usuário, sem prejuízo das sanções penais, acarretará: "I - o pagamento do valor atualizado do débito apurado, acrescido de multa de $10 \%$ (dez por cento) sobre seu valor, dobrada a cada reincidência; II - a cassação do direito de uso a critério do outorgante, a ser definida em regulamento".

No artigo 19, observa-se que: "das sanções de que trata o artigo anterior caberá recurso à autoridade administrativa competente, nos termos a serem definidos em regulamento."

\section{ANÁLISE E DISCUSSÃO DOS RESULTADOS}

Após a análise, foi possível observar que a cobrança pela utilização dos recursos hídricos em questão não pode ser caracterizada como um imposto, pois imposto não tem vinculação ao beneficiado, o dinheiro não tem destino, como demonstra o artigo 3 o da Lei Estadual $\mathrm{n}$ $12.183 / 2005$, no mínimo 50\% (cinquenta por cento) dos recursos de investimento oriundos da cobrança para conservação, proteção e recuperação das áreas de mananciais que atendam a sua área de atuação, deverão ser destinados pelo Comitê da Bacia Hidrográfica do Alto Tietê, durante período de 10 (dez) anos.

De acordo com Melo (2004, p. 76) a sistemática financeira concernente à descentralização da arrecadação das receitas públicas tem gerado dificuldades na precisa caracterização das contribuições. Este fato citado Poe Melo, demonstra estar presente, também, na situação analisada, pois este tributo não é caracterizado como taxa, uma vez que não há serviço prestado, nem ao menos colocado à disposição, também não apresenta valores estipulados para 
fornecimento de um serviço e nem representa o exercício regular do poder polícia.

Contribuição de melhoria, também, não pode ser caracterizada, pois nenhuma benfeitoria foi realizada.

O que se observa é que, na verdade, se trata de preço público, onde há uma preocupação legal com os investimentos para conservação, proteção e recuperação das áreas mananciais, inclusive com destinação de parte da arrecadação para o Comitê da Bacia Hidrográfica do Tietê.

Neste caso, é cobrado pelo Estado de São Paulo e outros estados estão seguindo este modelo, o que pode ocasionar uma guerra fiscal ou uma diferença de procedimento pelos estados.

\section{CONCLUSÕES}

Conforme a análise da Lei no 12.183, de 29 de dezembro de 2005, possibilitou compreender que a cobrança pela utilização dos recursos hídricos do domínio do Estado de São Paulo, caracteriza como uma cobrança com preço público, objetivando reconhecer que a água é um bem público de valor econômico e incentivar o uso racional e sustentável da água. A cobrança possui um caráter regulatório, ou seja, tem a finalidade de propor que a utilização dos recursos hídricos seja feita de forma consciente, levando em consideração que, embora seja um recurso natural, a água é sim um recurso esgotável, no qual se faz a urgente necessidade de controlar a sua utilização.

A aprovação da Lei foi relevante para o controle da utilização dos recursos, mas é necessária a criação de uma política de regulação federal. Desta forma, será possível impedir procedimentos diferenciados entre os órgãos públicos, evitando-se que a cobrança perca sua principal finalidade, que é regular, controlar e fiscalizar o uso racional da água.

A taxa pode ser cobrada pelos municípios, pelos estados ou pelo governo federal, portanto, desta forma é possível gerar até uma guerra fiscal. Uma alternativa para ser analisada é transformar em imposto e evitará a cobrança concorrente entre os poderes municipais, estaduais e federal, além de controlar medidas arbitrárias ou unilaterais dos governos.

A ideia de trabalhar essa política em um âmbito Federal é, exatamente, com o intuito de desenvolver uma verdadeira conscientização para atender determinadas necessidades ambientais, porém este aspecto deve ser mais discutido na sociedade.

Para finalizar, destaca-se que a pesquisa se constitui de uma discussão em construção, pois o processo de acompanhamento e controle de recursos hídricos tem muitas variáveis e, ainda, é algo que merece maior atenção pela sociedade. 


\section{REFERÊNCIAS BIBLIOGRÁFICAS}

Braga, C. Contabilidade ambiental: ferramenta para a gestão da sustentabilidade. São Paulo: Atlas, 2007.

Brasil. Constituição da República Federativa do Brasil: Promulgada em 5 de Outubro de 1988 / obra coletiva de autoria da Editora Saraiva com a colaboração de Antonio Luiz de Toledo Pinto, Márcia Cristina Vaz dos Santo Windt e Lívia Céspedes - 35. ed. atual. e ampl. - São Paulo: Saraiva, 2005. - (Coleção Saraiva de Legislação).

Lei № 5.172, de 25 de outubro de 1966. Denominado Código Tributário Nacional. Dispõe sobre o Sistema Tributário Nacional e institui normas gerais de direito tributário aplicáveis à União, Estados e Municípios. Brasília, 1966.

Cassone, V. Direito tributário: fundamentos constitucionais da tributação, classificação dos tributos, interpretação da legislação tributária, doutrina, prática e jurisprudência, atualizado até EC no 38, de 12-6-2002. 15 ed. São Paulo: Atlas, 2003.

São Paulo. Estado de. Lei Estadual no 12.183, DE 29 de dezembro de 2005. Dispõe sobre a cobrança pela utilização dos recursos hídricos do domínio do Estado de São Paulo, os procedimentos para fixação dos seus limites, condicionantes e valores e dá outras providências. Estado de São Paulo, 2005.

Estudos Avançados. A Disputa pela Água em São Paulo. Entrevista com Gerôncio Albuquerque Rocha. Estudos Avançados no. 17 (47), 2003. pp. 153- Disponível em: http://www.scielo.br/pdf/ ea/v17n47/a09v1747.pdf, acessado em 28/07/2013.

Fabretti, L. C. Contabilidade tributária. 9ạ ed. São Paulo: Atlas, 2005.

Direito tributário aplicado: impostos e contribuições das empresas. São Paulo: Atlas, 2006.

FABRETTI, L. C.; FABRETTI D. R. Direito Tributário: Para os Cursos de Administração e Ciências Contábeis. 6a ed. São Paulo: Atlas, 2007.

INSTITUTO SOCIOAMBIENTAL. http://www.socioambiental.org/esp/agua/pgn/noticias.html, acessado $28 / 07 / 2013$

JANUZZI. P. de M. SÃO PAULO, SÉCULO XXI: A MAIOR METRÓPOLE DAS AMÉRICAS. Ciência e Cultura. vol.56 no.2. São Paulo. Abril./Junho, 2004. Disponível em: http://cienciaecultura.bvs.br/ scielo.php?pid=S0009-67252004000200017\&script=sci_arttext, acessado em 28/07/2013. 
LEFF, E. Saber ambiental: sustentabilidade, racionalidade, complexidade, poder; tradução de Lúcia Mathilde Endlich Orth. Petrópolis, RJ: Vozes, 2001.

MELO, J. E. S. de. Curso de direito tributário. 5o ed. São Paulo: Dialética, 2004.

PAULSEN, L. Direito tributário: Constituição e Código Tributário à luz da doutrina e da jurisprudência. 7o ed. rev. atual. Porto Alegre: Livraria do Advogado: Esmafe, 2005.

RICHARDSON, R. J. Pesquisa social: métodos e técnicas. 3ำ ed. São Paulo: Atlas, 2007.

SANTOS, F. A.Ética e Responsabilidade Social - Uma Prática Cotidiana In: BARROS NETO, J. P. Administração de Organizações Complexas: liderando e simplificando a gestão para criar valor e maximizar resultados..1 ed.Rio de Janeiro : Qualitymark, 2009. p. 483-507.

SANTOS, F. de A.. Taylorismo e a responsabilidade ambiental das empresas. In: COSTA, Paulo Moreira da. Taylorismo: após 100 anos nada superou o modelo de gestão. Rio de Janeiro: Qualitymark, 2009.

SELBORNE, L. A ética do uso da água doce: um levantamento. Brasília: Unesco, 2002.

SUKHDEV, Pavan. Corporação 2020. São Paulo: Ed. Abril, 2013.

ZARPELON, M. I. Gestão e responsabilidade social: NBR 16.001/AS 8000: implantação e prática. Rio de Janeiro: Qualitymark, 2006.

VALENTIM, L. S. O. Recursos Hídricos, Saneamento e Saúde. Disponível em: http://www.cvs. saude.sp.gov.br/pdf/recursos_hidricos.pdf, acessado 28/07/2013. 